\title{
Calves Sex Ratio in Artificial and Naturally Bred Cattle at Adami Tulu Agricultural Research Center
}

\author{
Alemayehu Arega* Girma Chalchissa \\ Oromia Agricultural Research Institute, Adami Tulu Agricultural Research Center, \\ P.O.Box, 35, Batu/ Ziway, Ethiopia
}

\begin{abstract}
Breeding and calving records from 2013- 2016 maintained at Adami Tulu Agricultural Research center was used for current study with aim of assessing ratios of calves born and identifying some of the factors affecting ratios of calves born. The data was cleared, arranged, categorized and pulled into years and analyzed by using Statistical Package for Social Science Version 20.0 (SPSS). The probability of a male calf being born was analyzed by chi square test. A threshold significance level was determined at the $\mathrm{P}<0.05$. The result indicated that the overall sex ratio of calves born was i.e. the ratio of male to female is 57.1 to 42.9. Parity of the breeding cow doesn't have statistically significant effect on the sex ratio of calves born. The statistically analysis also shows that breeding year and season had not have the significant effect the sex ratio of calves born. In addition the sire line with which the animals inseminated has no significant effect. The result also indicted for the presence of significant difference of breeding method on sex ratio of calves born. From this it was concluded that breeding method has a significant effect on sex ratio of calves born in which number of male calves were higher in animals inseminated artificial and vice versa. Modern dairy reproductive technologies which enables to get more number of female calves has to be look into consideration to increase number of female animals for dairy producers in addition to providing efficient artificial insemination service in the country.
\end{abstract}

Keywords: Calf sex ratio, Breeding method, Adami Tulu

DOI: $10.7176 / \mathrm{JBAH} / 9-1-01$

\section{Introduction}

Sex ratio theory is defined as the ratio of male-to-female offspring at birth, which ideally should be equal, which is one of the more developed areas of evolutionary biology. In livestock production, the possibility to modify the sex ratio of the calf can result in a substantial increase in the production in livestock farms. Secondary sex ratio (SSR) is defined as the number of male calves born divided by the total number of individuals (both male and female calves born) (Mora et al., 2010).

The sex of calf is ultimately determined by the presence or absence of a Y chromosome in fertilizing sperm cell. It a Y chromosome is present in fertilizing sperm cells, then the calf will be male and if the $\mathrm{Y}$ chromosome is absent in fertilizing sperm, the calf will be female (John et al., 2002).

The effectiveness of selection and genetic improvement programs can be sensibly enhanced by the manipulation of sex ratio offspring born through the differential increase in the number of females or males calves (Seidel 2003).

The study by Sarzamin Khan et al., (2012) indicated that altering secondary sex ratio in cattle is financially attractive. In commercial dairy cattle production where a high number of female calves is desirable sex ratio is the major trait of economic importance.

Demiral et al., (2007) indicated that sex ratio was influenced by many factors such as maternal age, parity, stress, litter size, birth season, time of insemination, managerial conditions, inbreeding levels and population demography in mammals other than human being.

In Ethiopia artificial insemination is one of the reproductive technologies commonly used by dairy producers with the aim of increasing the number of improved crossbred dairy cows for last five decades. Studies by Bekele (2005) and Frehiwet et al., (2014) reported that many of the small scale and modern dairy farm owners in different areas of Ethiopia have been complaining about the increment of the probability of male calves born following artificial insemination in addition to its lower efficiency (Desalegne et al., 2009). The objective of this paper is to assess calf sex ratios of calves born with in the period of $2013-2016$ breeding periods and identify some of factors affecting sex ratio and their association with calf sex ratios.

\section{Materials and Methods Study area}

The study was conducted at Adami Tulu Agricultural Research center located at $167 \mathrm{~km}$ south of Addis Ababa and situated at latitude of $7^{0} 9^{\prime} \mathrm{N}$ and $38^{0} 7^{\prime} \mathrm{E}$ longitude in semi-arid middle rift valley of Ethiopia. The area is situated at 1500 meters above sea level and the soil type of the area is fine, sandy loam with sand, clay in the proportion of $34: 48: 18$ respectively. The average annual rain fall is $760 \mathrm{~mm}$. The minimum and maximum temperature are 12.6 and $27^{\circ} \mathrm{c}$, respectively (ATARC, 2003). 


\section{Experimental animal selection and management}

Arsi cows reared on station were selected based on their age, parity and body condition. They were used as a dam line for the study. The semen of different sire of Holstein Frisian breed was used as a sire line. All animals were supplemented with concentrates before they were used for breeding purpose in addition to grazing on natural grazing land daily for eight hours.

Heat detection: All animals were monitored by both herdsmen at day time and night guards for signs of heat in order increase the efficiency of heat detection.

\section{Breeding}

A standard semen handling and insemination procedure recommended by IAEA (2005) was used to inseminate animals. Cows noted in heat in the morning were inseminated that afternoon and those identified in the afternoon were inseminated the next morning based on the "AM- PM guideline" (Peter and Ball, 1995).

\section{Statistical analysis}

Data management

For this study four year (2014 to 2017) breeding records were used. The data was maintained at ATARC dairy team. Then the data was cleared, arranged, categorized and pulled into years and finally processed to Microsoft excel work book for easily management. Then imported and analyzed by using Statistical Package for Social Science Version 20.0 (SPSS).The Chi-square $\left(\chi^{2}\right)$ test procedure of SPSS Version 24.0 was used to analyze the qualitative data. The probability of a male calf being born was analyzed by chi square test. A threshold significance level was determined at the $\mathrm{P}<0.05$. Sex ratio was calculated as proportion of males against 100 female.

\section{Results and Discussions}

The result pertains to overall sex ratio of calves born is indicated in figure 1. In current study the overall sex ratio i.e. the ratio of male to female is 57.1 to 42.9 with favoring the birth of bull calves. The current findings are in agreement with findings by Bekele, (2005); Frehiwot T et al., (2014) for the increment of male calf sex born following artificial insemination in different parts of Ethiopia but the current figure is higher than the figure they reported. On the other hand in contrary to the current findings (Delesa et al., 2014) reported that there were no differences across the sexes of the calves born from artificial insemination and natural mating.

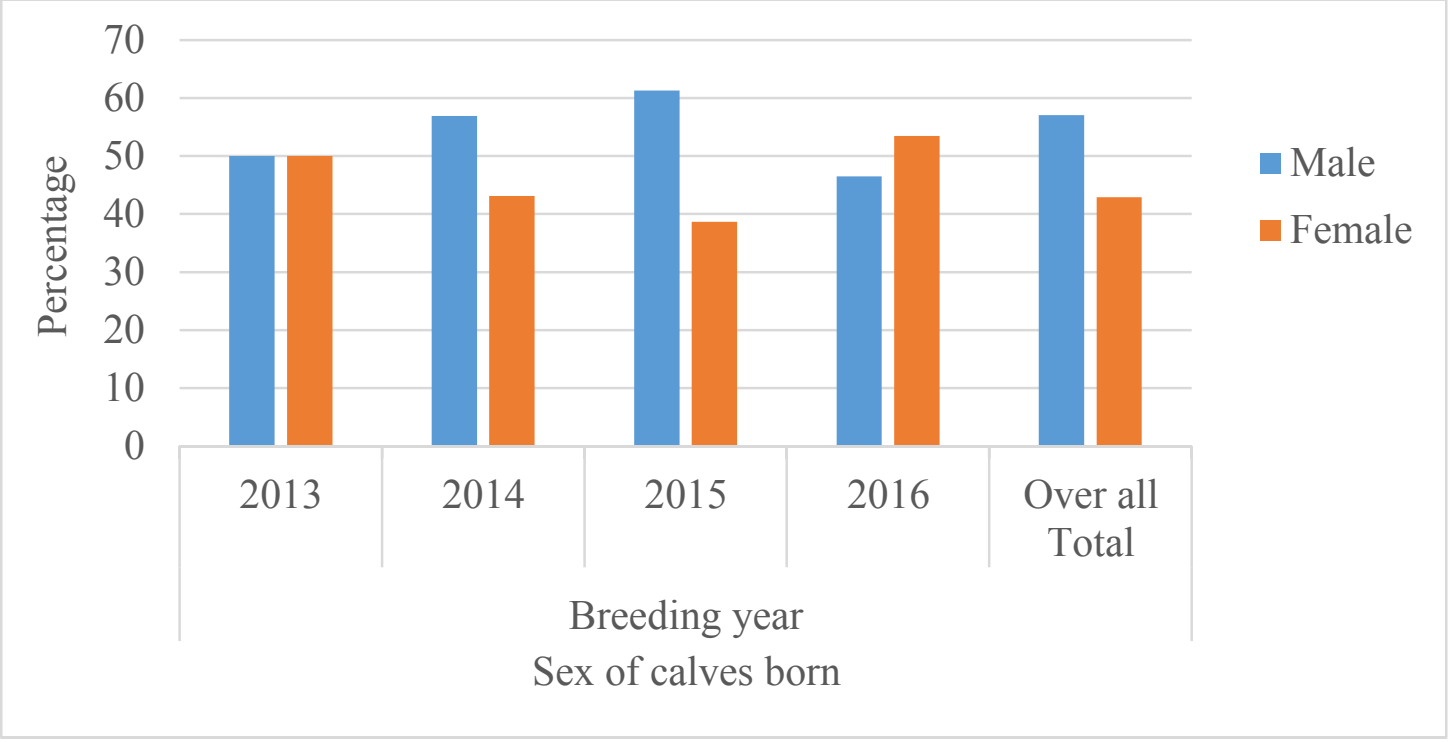

Figure 1. Overall sex ratio of calves born

\section{Effect of breeding method on sex ratio}

The result pertains to effects of breeding methods on sex ratio is presented on table 1 . The result indicted for the presence of significant difference of breeding method on sex ratio of calves born. The number of female calves were higher in those animals served with bull (natural mating) whereas the reverse true in case of artificial insemination. The current findings are in agreement with findings by Bekele, (2005); Frehiwot T et al., (2014) who's reported for the increment of male calf sex born following artificial insemination in different parts of Ethiopia. On the other hand in contrary to the current findings (Delesa et al., 2014) reported that there were no differences across the sexes of the calves born from artificial insemination and natural mating. 
Table 1. Effects of breeding method on sex ratio

\begin{tabular}{|c|c|c|c|}
\hline \multirow[t]{2}{*}{ Calf sex } & \multicolumn{2}{|c|}{ Breeding method } & \multirow[t]{2}{*}{ Chi square $X^{2}$} \\
\hline & Natural mating & $\mathrm{AI}$ & \\
\hline \multicolumn{4}{|l|}{ Male } \\
\hline $\mathrm{N}$ & 45 & 128 & \\
\hline$\%$ & 43.7 & 57.1 & 0.024 \\
\hline \multicolumn{4}{|l|}{ Female } \\
\hline $\mathrm{N}$ & 58 & 96 & \\
\hline$\%$ & 56.3 & 42.9 & \\
\hline
\end{tabular}

Effects of breeding cow's parity on the sex ratio

Table 2. Effects of parity of breeding cows on sex of calves born

\begin{tabular}{|c|c|c|c|c|c|c|}
\hline \multirow[t]{2}{*}{ Calf sex } & \multicolumn{5}{|c|}{ Parity } & \multirow{2}{*}{ Chi square $\left(X^{2}\right)$} \\
\hline & 1 & 2 & 3 & 4 & Total & \\
\hline \multicolumn{7}{|l|}{ Male } \\
\hline $\mathrm{N}$ & 54 & 45 & 13 & 8 & 120 & 0.286 \\
\hline$\%$ & 61.4 & 52.3 & 46.4 & 72.7 & 56.3 & \\
\hline \multicolumn{7}{|l|}{ Female } \\
\hline $\mathrm{N}$ & 34 & 41 & 15 & 3 & 93 & \\
\hline$\%$ & 38.6 & 47.7 & 53.6 & 27.3 & 43.7 & \\
\hline
\end{tabular}

As presented on table 2 parity of the breeding cow doesn't have statistically significant effect on the sex ratio of calves born. XU et al., 2000 in their study on New Zealand dairy cattle indicated that only the little is known on the effect of service sire breed on secondary sex ratio and although reported that the heritability estimates of sex ratio have been $2 \%$. The current result was not agreed with findings of different scholars. Berry and Cromie (2007) reported that the probability of a male calf being born was significantly higher in older cows compared to younger cows. Goshu and Singh (2013), also indicated that the proportion of female calves born was $48 \%$ at first calving/parity and later ranged from $44 \%$ to $51 \%$ from second calving and fifth to seventh calving respectively. On the other hand the current result is in concise the findings of Kaygisiz et al. (2003), and Roche et al. (2006) reported that there was no effect of the number of calving on the sex ratio of calves born. The study conducted by Yilmaz et al., (2010) in Malya and Konuklar state farm in Turkiye indicated that there was no significant association between parity and sex of calves born.

Breeding season and year effects on sex ratio

Table 3. The effects of breeding season on sex of calves born

\begin{tabular}{|c|c|c|c|c|c|}
\hline \multirow[t]{2}{*}{ Calf sex } & \multirow[b]{2}{*}{ Rainy } & \multicolumn{3}{|c|}{ Breeding season } & \multirow[t]{2}{*}{ Chi square $\mathrm{X}^{2}$} \\
\hline & & Short rainy & Dry & Total & \\
\hline \multicolumn{6}{|l|}{ Male } \\
\hline $\mathrm{N}$ & 72 & 5 & 51 & 128 & \\
\hline$\%$ & 62.9 & 41.7 & 52.6 & 57.1 & 0.182 \\
\hline \multicolumn{6}{|l|}{ Female } \\
\hline $\mathrm{N}$ & 43 & 7 & 46 & 96 & \\
\hline$\%$ & 37.4 & 58.3 & 47.4 & 42.9 & \\
\hline
\end{tabular}

As presented on table 3 above there result indicates that the sex ratio of calves born was doesn't affected by the season in which animals were inseminated (bred). The statistically analysis also shows for the absence of significant difference between the sex ratio of calves born. The current result was in consices with the findings by Yilmaz et al., (2010) in Konuklar state farm in Turkiye but the same author reports the presence of association between sex ratio of calves born and breeding season Malya state farm. In contrast to the current result different authors in different parts of the world indicates that the association between sex ratio of calves born and breeding season was significant. Alemayehu et al, (2018) in their study indicated that the sex ratio of calves born was significantly different between the breeding seasons and reported that the sex of male calves born was higher in rainy season whereas the reverse was true in dry season. The findings by Singh et al., (2004) also indicated calving season to have a slight effect on the sex ratio of the calves. Roche et al. (2006) reported that the probability of a male calves being born increased with increasing air temperature and humidity around the time of conception.

The main reason for the difference in the result might be due to nutrition supplement for the animals and environmental factors across the study season in the areas. Rosenfeld and Roberts, (2004) in their review about factors affecting sex ratio females in better body condition would produce more male than female progeny. Dairy cows, but not heifers, on a high plane of nutrition give birth to proportionately more bull than female calves than cows on a poorer diet. 
As indicated in table 4 below there is no significant difference on the sex ratio of calves born between breeding years in which the ratio of bull calves born are higher than the female calves with in each breeding years.

Table 4. Effects of breeding year on sex ratio of calves born

\begin{tabular}{|c|c|c|c|c|c|c|}
\hline \multirow[t]{2}{*}{ Calf sex } & \multicolumn{5}{|c|}{ Breeding year } & \multirow[t]{2}{*}{ Chi square $X^{2}$} \\
\hline & 2013 & 2014 & 2015 & 2016 & Total & \\
\hline \multicolumn{7}{|l|}{ Male } \\
\hline $\mathrm{N}$ & 2 & 33 & 73 & 20 & 128 & 0.403 \\
\hline$\%$ & 50 & 56.9 & 61.3 & 46.5 & 57.1 & \\
\hline \multicolumn{7}{|l|}{ Female } \\
\hline $\mathrm{N}$ & 2 & 25 & 46 & 23 & 96 & \\
\hline$\%$ & 50 & 43.1 & 38.7 & 53.5 & 42.9 & \\
\hline
\end{tabular}

\section{Sire line effects on sex ratio of calves}

The result pertains to effect of sire on sex ratio was presented on table 5. The result indicated that there is no significant difference in the sex ratio of calves born between different sires. The current result is in agreement with the findings of (John et al., 2002) who reports sire has no effect on sex ratio of calves born and indicated that sex ratios in calves born from a particular ejaculate of a bull can be observed in the calves that are born. Sex ratio in offspring did not differ between sires, but was different from ejaculate to ejaculate within a sire, for both swine and dairy cattle. In contrary to the current findings (Kaygisiz et al., 2003; Yilmaz et al., 2010) reported for the presence of sire effect on sex ratio of calves born.

Table 5 . The effects of sire on sex ratio of calves born.

\begin{tabular}{lllll}
\hline Sire lines & \multicolumn{2}{c}{ Sex of calves } \\
& $\mathrm{N}$ & Female & $\mathrm{N}$ & $\begin{array}{c}\text { Male } \\
\%\end{array}$ \\
\hline $10-238$ & 27 & 43.5 & 35 & 56.5 \\
$10-251$ & 11 & 50 & 11 & 50 \\
Amazon & 6 & 31.6 & 13 & 68.4 \\
Bruce & 13 & 56.5 & 10 & 43.5 \\
Garret & 5 & 50 & 5 & 50 \\
Jovan & 5 & 29.4 & 12 & 70.6 \\
Kodak & 0 & 0 & 3 & 100 \\
Lache & 11 & 40.7 & 16 & 59.3 \\
Larame & 5 & 50 & 5 & 50 \\
Leno & 12 & 40 & 18 & 60 \\
Total & 95 & 42.2 & 130 & 57.8 \\
$X^{2}$ value & & & .553 & \\
\hline
\end{tabular}

\section{Conclusions}

The overall sex ratio i.e. the ratio of male to female is 57.1 to 42.9 with favoring the birth of bull calves. Breeding method has a significant effect on the sex ratio of calves born in which more number of female calves was born from natural mating than animals inseminated artificially. In dairy sector whereby more number of female animals are required for milk production using natural method is more advantageous.

On the other hand parity of the dam, breeding season, year and sire had no significant effect on the sex ratio of calves born.

Further detail studies has to be done on identifying the reason for difference in sex ratio of calves born between natural and artificial breeding methods.

Modern reproductive technologies which enables to alter the sex ratio of claves born especially those favoring the birth of female calves has to be evaluated and available for dairy producers at different levels in our country in addition to providing artificial insemination service.

\section{References}

ATARC, 2003. Adami Tullu Agricultural Research Center, strategic planning and management document, P. 67.

Bekele, T., 2005. Calf Sex Ratios in Artificially Inseminated and Natural Mated Female Crossbred Dairy Herd. In: proceedings of the 13 annual conference the Ethiopian Society of Animal Production. Addis Ababa, Ethiopia, pp: 225-230.

Berry D.P., Cromie A.R., 2007. Artificial insemination increases the probability of a male calf in dairy and beef cattle. Theriogenology 67, 346-352. 
Cheryl S. Rosenfeldand R. Michael Roberts, 2004. Maternal Diet and Other Factors Affecting Offspring Sex Ratio: A Review Departments of Animal Sciences,2 Biomedical Sciences,3 and Biochemistry,4 University of Missouri-Columbia, Columbia, Missouri 65211 Biology of reproduction 71, 1063-1070 (2004) Published online before print 30 June 2004.

D.P. Berry, A.R. Cromie, (2006), Artificial insemination increases the probability of a male calf in dairy and beef cattle, Theriogenology doi:10.1016/j.theriogenology.2006.08.003

Delesa EK, Yohannes A, Alemayehu M, Samuel T, Yehualaeshet T, 2014. Calves' sex ratio in naturally and artificially bred cattle in central Ethiopia Ethiopian Institute of Agricultural Research, Holetta Agricultural Research Center, Holetta, Ethiopia College of Veterinary Medicine, Nursing and Allied Health (CVMNAH), Department of Pathobiology, Tuskegee University, USA Theriogenology. 2014 Aug; 82 (3):433-9. DOI:10.1016/j.theriogenology.2014.04.027 Epub 2014 May 9.

Demiral O., Ün M., Abay M., Bekyürek T., 2007. The effect of artificial insemination timing on the sex ratio of offspring and fertility in dairy cows. Turk. J. Vet. Anim. Sci.31, 21-24.

Desalegn, G., B. Merga, T. Azage and B. Kelay, (2009).Status of artificial insemination service in Ethiopia. In:The 17th Annual Conference of the Ethiopian Society of Animal Production (ESAP), Sept 24-26, 2009 AddisAbaba, Ethiopia, pp: 87-104.

Frehiwet Tesfu, Berihu Gebrekidan and Berihun Afera, (2014) Assessment and Comparison of Sex Ratio Following Artificial Insemination and Natural Mating in Small Scale and Modern Dairy Cattle Farms in Mekelle. Journal of Reproduction and Infertility 5 (2): 58-64, DOI: 10.5829/idosi.jri.2014.5.2.84277

Goshu G., Singh H., 2013. Genetic and non-genetic parameters of replacement rate component traits in Holstein Friesian cattle. Springer Plus 2, 581

I. Yilmaz, E. Eyduran and A. Kaygisiz, 2010. Determination of Some Environmental Factors Related to Sex Ratio of Brown Swiss Calves The Journal of Animal \& Plant Sciences, 20(3), 2010, Page: 164-169 ISSN: 1018-7081

IAEA (2005). Improving artificial breeding of cattle in Africa. Guidelines and recommendations. A manual prepared under the framework of an IAEA Technical Cooperation Regional AFRA Project on Increasing and Improving Milk and Meat Production, with technical support from the Joint FAO/IAEA Division of Nuclear Techniques in Food and Agriculture.

John E. Chandler, R. Wayne Adkinson and E. Barry Moser, 2000. Male Offspring Distributions in Calving and Farrowing Data.

Kaygisiz, A., Vanli Y., Cakmak L., 2003. Estimates of genetic and phenotypic parameters of sex ratio in Holstein cattle. GAP III. Agricultural Congress, Sanliurfa, Turkey.

Roche J.R., Lee J.M., Berry D.P., 2006. Climatic factors and secondary sex ratio in dairy cows. J. Dairy Sci. 89, $3221-3227$

Seidel, G.E. 2003. Economics of selecting for sex: The most important genetic trait. Theriogenology, 59: pp 585598

Z. Z. Xu, D. L. Johnson and L. J. Burton, 2000. Factors affecting the sex ratio in dairy cattle in New Zealand. ISSN 0370-2731/2000 Proceedings of the New Zealand Society of Animal Production 60: 301-302 